\title{
ARTICLE
}

Received 20 Aug 2012 | Accepted 22 Oct 2012 | Published 27 Nov 2012 DOl: 10.1038/ncomms2223

\section{Identification and characterization of polyclonal $\alpha \beta-T$ cells with dendritic cell properties}

Mirela Kuka', Ivana Munitic ${ }^{1} \&$ Jonathan D. Ashwell ${ }^{1}$

An efficient immune response requires coordination between innate and adaptive immunity, which act through cells different in origin and function. Here we report the identification of thymus-derived $\alpha \beta$-T-cell receptor ${ }^{+}$cells that express CD11c and major histocompatibility complex class II, and require FLT3 ligand for development ( $\left.T_{D C}\right)$. $T_{D C}$ express genes heretofore found uniquely in T cells or dendritic cells, as well as a distinctive signature of cytotoxicity-related genes. Unlike other innate T-cell subsets, $T_{D C}$ have a polyclonal T-cell receptor repertoire and respond to cognate antigens. However, they differ from conventional $T$ cells in that they do not require help from antigen-presenting cells, respond to Toll-like receptor-mediated stimulation by producing interleukin-12 and process and present antigen. The physiological relevance of $T_{D C}$, found in mice and humans, is still under investigation, but the fact that they combine key features of $T$ and dendritic cells suggests that they provide a bridge between the innate and adaptive immune systems.

\footnotetext{
${ }^{1}$ Laboratory of Immune Cell Biology, Center for Cancer Research, National Cancer Institute, National Institutes of Health, Bethesda, MD 20892, USA. Correspondence and requests for materials should be addressed to J.D.A. (email: jda@pop.nci.nih.gov).
} 
A $\mathrm{n}$ efficient immune response requires coordination between innate and adaptive immunity ${ }^{1}$. In particular, crosstalk between dendritic cells (DCs) and T cells is key in the initiation of adaptive immunity ${ }^{2}$, and both of those cell types are thought to have clearly distinct roles during this process. DCs, the most efficient antigen-presenting cells (APCs), process and present pathogen-associated antigens in the form of peptides loaded on major histocompatibility complex (MHC) molecules. The course of a particular adaptive immune response is shaped by the maturation and activation status of DCs, with immature DCs leading to tolerance and mature DCs to efficient immune responses. One way DCs are induced to mature is ligation of pattern-recognition receptors by specific microbial-associated patterns ${ }^{3}$, which results in upregulation of costimulatory molecules and MHC-II, as well as production of pro-inflammatory cytokines such as IL-12 and tumour necrosis factor- $\alpha$. On maturation, DCs migrate to T-cell areas in the peripheral lymphoid organs, where they present antigen loaded on MHC-II molecules to $\mathrm{CD} 4{ }^{+} \mathrm{T}$ cells. Some DCs are also very efficient in cross-presentation of viral or endogenous peptides on MHC-I molecules to $\mathrm{CD}^{+}{ }^{+} \mathrm{T}$ cells. Recognition of MHC complexes by the $\mathrm{T}$-cell receptor (TCR) combined with costimulation provided by mature DCs results in a complete and effective adaptive T-cell response ${ }^{2}$.

Although both arise from bone marrow progenitors, the developmental paths of DCs and T cells diverge early and are thought to be as distinct as their functions. Conventional DCs (cDCs) originate from a common DC progenitor in the bone marrow and migrate to peripheral lymphoid organs ${ }^{4}$. Transcription factors such as PU.1, Ikaros, IRF8, RelB and Batf 3 have been implicated in DC development, but due to their pleiotropic role and the high heterogeneity of DC subsets none of these can be used to exclusively define the DC lineage ${ }^{5,6}$. Two recent papers reported that the transcription factor Zbtb46 is expressed by cDCs throughout their differentiation, and is a specific marker for cDCs among immune cells ${ }^{7,8}$. Although no master regulator of DC lineage commitment has been described, interactions of FLT3 with its ligand (FLT3L) are necessary for DC development and homeostasis, because FLT3L-deficient mice lack DCs in peripheral lymphoid organs ${ }^{9}$.

In contrast to DCs, T-cell commitment occurs in the thymus, where $\mathrm{T}$-cell precursors undergo a multi-step process that leads to the generation of mature $\mathrm{CD} 4{ }^{+} \mathrm{CD} 8{ }^{-}$and $\mathrm{CD} 4{ }^{-} \mathrm{CD} 8{ }^{+}$ $\mathrm{T}$ cells ${ }^{10,11}$. The most immature thymocytes are $\mathrm{CD} 4^{-} \mathrm{CD} 8^{-}$ (double negative (DN)) and can be separated into four different populations (DN1-4) based on expression of CD44 and CD25. DN1-DN2 thymocytes retain the plasticity to give rise to some myeloid cell types, including natural killer (NK) cells and thymic $\mathrm{DCs}^{11-14}$. Commitment to the T-cell lineage, and the subsequent recombination of the TCR $\beta$ locus and pre-TCR expression, takes place at the DN3 stage (CD25 $\left.{ }^{+} \mathrm{CD} 44^{-}\right)$, is Notch-dependent, and subsequent to the silencing of a number of transcription factors important for myeloid development, most notably PU. $1^{14}$.

Although innate and adaptive immune systems have been thought to act through different cells and mechanisms, recent studies provide several examples in which these two arms of the immune system appear to overlap. For example, some thymusselected T cells, such as NK T cells ${ }^{15}$ and most $\gamma \delta$-T cells ${ }^{16}$, are considered innate because of their limited TCR repertoire and prompt responses to non-peptide antigens. There is also evidence that some T cells can express low but detectable levels of Toll-like receptors (TLRs) ${ }^{17}$, which are normally involved in maturation and activation of DCs and other innate immune cells ${ }^{3}$. However, the outcome of TLR triggering in T cells is different from that in innate immune cells, being confined to increased survival and costimulation $^{17,18}$.
These observations prompted us to ask whether there exist cells that truly combine the molecular and functional characteristics of innate and adaptive immunity. We have identified a novel population of thymus-derived cells that, like DCs, require FLT3L for development and exhibit surface markers and functions of both DC and T cells $\left(\mathrm{T}_{\mathrm{DC}}\right)$. Molecular profiling revealed that $\mathrm{T}_{\mathrm{DC}}$ express genes characteristic of DCs, $T$ cells and cytotoxic cells. $T_{D C}$ expressed polyclonal $\alpha \beta$-TCRs and responded to antigen, but unlike conventional T cells did not require help from APCs. Strikingly, $\mathrm{T}_{\mathrm{DC}}$ responded to TLR-mediated stimulation by producing IL-12, and were able to process and present antigen to MHC-II-restricted T cells.

\section{Results}

Identification of cells expressing DCs and T-cell markers. Conventional murine DCs express high levels of CD11c and MHC-II. Interestingly, we found that around 7\% of splenic DCs expressed $\alpha \beta$-TCR, a distinguishing characteristic of conventional $\alpha \beta$-T cells (Fig. 1a). These cells comprised $0.04 \%$ of spleen and $0.06 \%$ of lymph node cells (Fig. $1 \mathrm{~b}$ ), and because they expressed T-cell and DC, but not other lineage markers (Fig. 1c), were termed $\mathrm{T}_{\mathrm{DC}}$. $\mathrm{T}_{\mathrm{DC}}$ were positive for T-cell markers such as Thy-1, $\mathrm{CD} 27$, and either CD4 or CD8 $\beta$ at the same ratio as conventional $\mathrm{T}$ cells (Fig. 1d,e). $\mathrm{T}_{\mathrm{DC}}$ had a polyclonal $\mathrm{V} \beta$ repertoire comparable to conventional $\alpha \beta$-T cells (Fig. 1f), in marked contrast to previously described semi-invariant innate T-cell subsets ${ }^{15}$. As CD11c can be expressed on activated $\mathrm{T}$ cells in some infectious settings ${ }^{19-21}$, we asked whether $\mathrm{T}_{\mathrm{DC}}$ might represent a subset of activated $\mathrm{T}$ cells. $\mathrm{T}_{\mathrm{DC}}$ displayed neither signs of recent activation $\left(\mathrm{CD} 69^{-} \mathrm{CD}^{-} 5^{-} \mathrm{IL}-7 \mathrm{R}^{\mathrm{hi}}\right)$ nor showed an increase in T-cell memory markers CD122 or CXCR3 (Fig. 1g). The homing molecules CCR7 and CD62L were expressed similarly in T cells and $\mathrm{T}_{\mathrm{DC}}$, but not in DCs. In fact, expression levels of all of the tested T-cell markers on $\mathrm{T}_{\mathrm{DC}}$ mirrored the levels on $\mathrm{T}$ cells. One activation/memory $\mathrm{T}$-cell marker, $\mathrm{CD} 44$, was expressed on $\mathrm{T}_{\mathrm{DC}}$, but was expressed equally on DCs, and thus in this case cannot be considered a T-cell marker. Staining for DC markers revealed that $\mathrm{T}_{\mathrm{DC}}$ expressed CD11c, MHC-II, CD11b, F4/80 and FCR $\gamma$ at intermediate levels with respect to cDCs (Fig. $1 \mathrm{~h}$ and Supplementary Fig. 1a) whereas non-DC-specific markers such as MHC-I and CD45 were expressed at similar levels (Supplementary Fig. 1a). To test whether $\mathrm{T}_{\mathrm{DC}}$ are $\mathrm{T}$ cells that acquired $\mathrm{DC}$ markers through intercellular transfer ${ }^{22}$, cells from a reporter mouse that reveal transcriptional regulation of $\mathrm{CD} 11 \mathrm{c}$ were examined. Just as with cell surface CD11c (Fig. 1h), $\mathrm{T}_{\mathrm{DC}}$ enhanced green fluorescent protein (EGFP) expression driven by the CD11c promoter was at levels intermediate between $\mathrm{T}$ cells and DCs (Fig. 2a and Supplementary Fig. 1b). Furthermore, highly purified (Supplementary Fig. 1c) $\mathrm{T}_{\mathrm{DC}}$ expressed Ciita, which regulates transcription of MHC-II and is not expressed by murine $\mathrm{T}$ cells $^{23}$ (Fig. 2b). In the obverse approach, a GFP reporter driven by the Thpok-regulatory elements, a transcription factor active in CD4 $\mathrm{T}$ cells ${ }^{24}$, was expressed in $\mathrm{CD}^{+}{ }^{+}$but not $\mathrm{CD} 8{ }^{+} \mathrm{T}_{\mathrm{DC}}$ (Fig. 2c). Therefore, expression of cell surface $\mathrm{T}$ and DC markers in $\mathrm{T}_{\mathrm{DC}}$ is a reflection of their transcriptional regulation.

FLT3L is a hematopoietic growth factor often used to expand DCs in vivo ${ }^{25}$. To test whether $\mathrm{T}_{\mathrm{DC}}$ resemble $\mathrm{DCs}$ in this regard, after assessing that $\mathrm{T}_{\mathrm{DC}}$ express FLT3 (Fig. 2d, left), C57BL/6 (B6) mice were injected with B16-FLT3L melanoma cells. As described for $\mathrm{cDCs}^{25,26}, \mathrm{~T}_{\mathrm{DC}}$ downregulated FLT3 (Fig. 2d, right) and expanded in response to FLT3L, resulting in a five to sixfold increase in frequency (Fig. 2e). FLT3L-expanded $\mathrm{T}_{\mathrm{DC}}$ had a cell surface phenotype identical to $\mathrm{T}_{\mathrm{DC}}$ in 
a

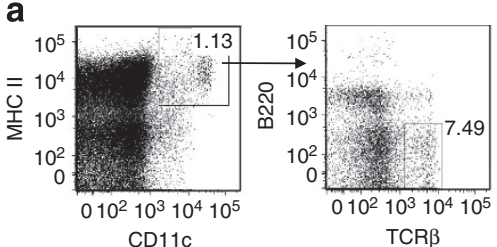

b

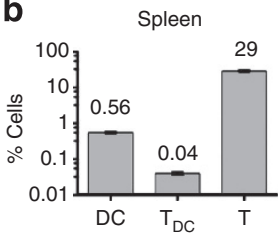

C
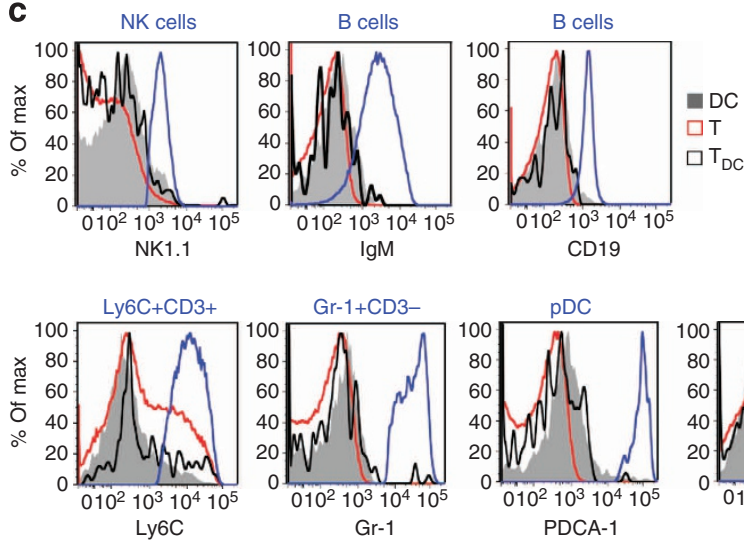
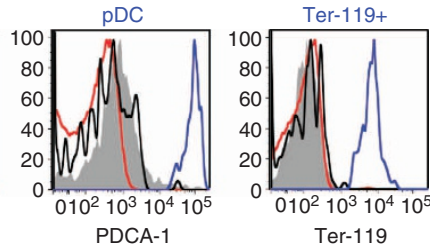

d

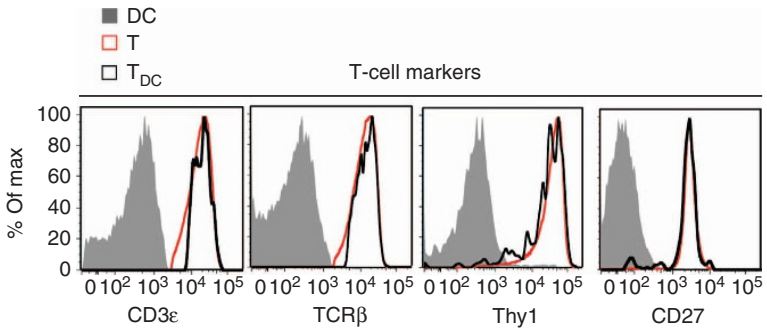

e

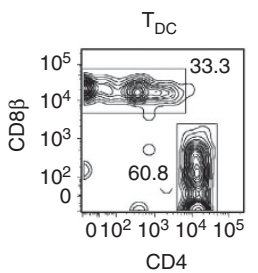

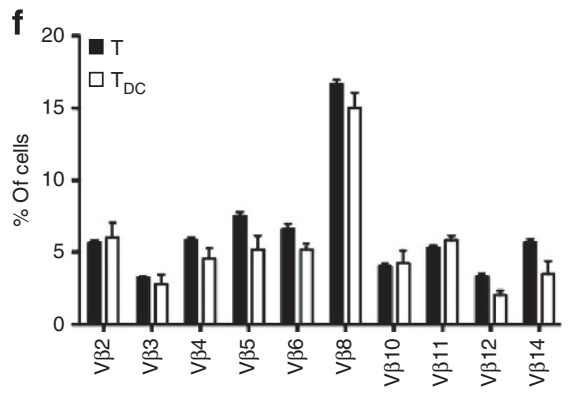

g

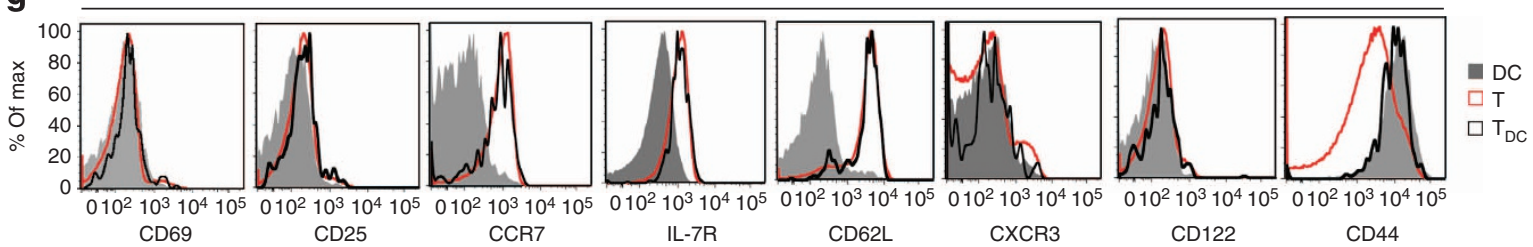

h

DC markers

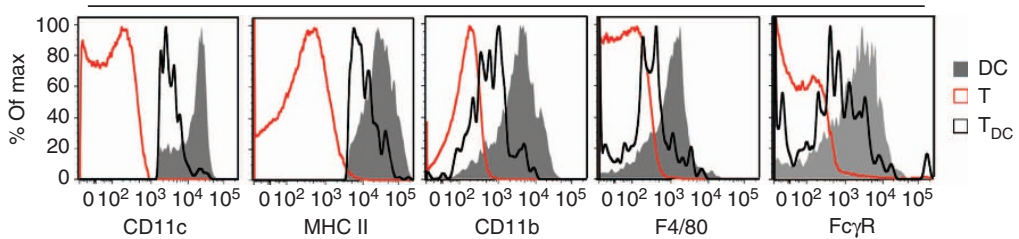

Figure 1 | Identification of murine cells expressing T-cell and DC markers ( $\mathbf{T}_{\mathbf{D C}}$ ). (a) Gating strategy for identification of $\mathrm{T}_{\mathrm{DC}}$ from B6 splenocytes. (b) The frequencies of the indicated subsets are shown in spleen and lymph nodes of at least 10 B6 mice. Mean \pm s.e.m. is represented for each cell subset. (c-h) Surface marker expression by the indicated subsets from B6 splenocytes. (f) Mean \pm s.e.m. of three mice is represented for each marker.

unmanipulated mice (data not shown), and were used in experiments when indicated. We considered the possibility that $\mathrm{T}_{\mathrm{DC}}$ represented rare $\mathrm{T}$-cell/DC doublets that escaped doublet discrimination detection (Supplementary Fig. 1d). Arguing against this was that the levels of the T-cell markers on $\mathrm{T}_{\mathrm{DC}}$ were indistinguishable from conventional $\alpha \beta$-T cells, whereas DC markers were intermediate between T cells and DCs. Moreover, a radiation bone marrow chimera showed that each newly generated $\mathrm{T}_{\mathrm{DC}}$ displayed only one of the two congenic markers, never both, indicating that they are not T/DC conjugates (Supplementary Fig. 1e). Perhaps the best evidence came from imaging highly purified $\mathrm{T}_{\mathrm{DC}}$ by confocal microscopy (Fig. 2f). Whereas T cells were $\mathrm{TCR}^{+} \mathrm{CD} 11 \mathrm{c}^{-} \mathrm{MHC}^{-\mathrm{II}^{-}}$and DCs were $\mathrm{TCR}^{-} \mathrm{CD} 11 \mathrm{c}^{+} \mathrm{MHC}^{-\mathrm{II}^{+}}$, each $\mathrm{T}_{\mathrm{DC}}$ bore all three markers. $\mathrm{T}_{\mathrm{DC}}$ size and morphology was similar to $\mathrm{T}$ cells, not DCs, suggesting that they are a novel subset of $\mathrm{T}$ cells with innate cell characteristics.
$T_{D C}$ have a unique gene signature. cDNA microarray analyses were performed to provide a non-biased assessment of $T_{D C}$ gene expression, and revealed that $\mathrm{T}_{\mathrm{DC}}$ have a clearly distinct genetic profile (Fig. 3a). $T_{D C}$ expressed many genes encoding proteins normally found in T cells (for example, Lck, CD3 subunits and IL-7R $\alpha$ ) or DCs (CD83, MHC-II, FLT3 and Zbtb46), but not both (Tables 1 and 2). Many of the cell surface proteins identified by microarray were among those detected on $\mathrm{T}_{\mathrm{DC}}$ in Fig. 1. In addition, $\mathrm{T}_{\mathrm{DC}}$ expressed Itgal (encoding $\mathrm{CD} 11 \mathrm{a}$, the $\alpha$ chain of the integrin LFA-1, which is upregulated in activated T cells) at levels comparable to those of DCs and unstimulated T cells (data not shown). PU-1 (encoded by Sfpi1) is a myeloid lineage-related transcription factor ${ }^{5}$, and Zbtb46 has recently been shown to be expressed specifically in DCs ${ }^{7,8}$. Their expression in $T_{D C}$ and DCs but not $\mathrm{T}$ cells was validated by reverse transcription (RT)-PCR (Fig. 3b). Interestingly, some $\mathrm{T}_{\mathrm{DC}}$-associated genes were expressed at much higher levels than in T cells or DCs. Among 
a

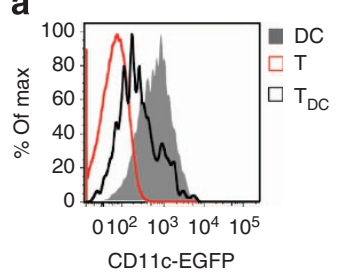

b

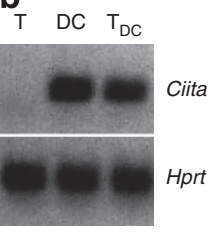

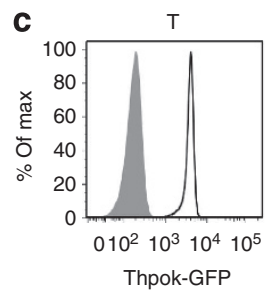

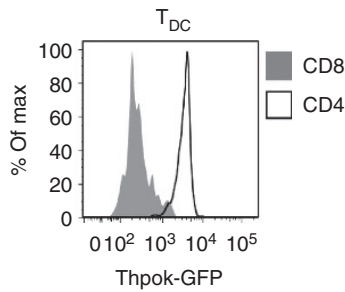

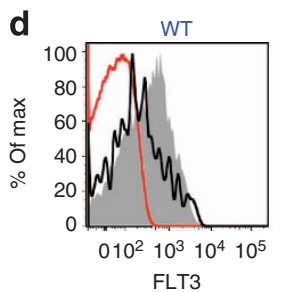
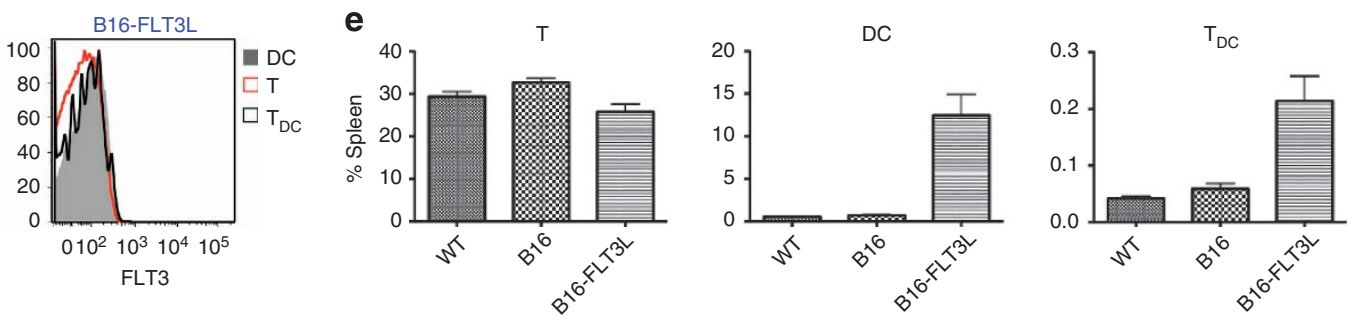

f

CD11c

MHC II

TCR $\beta$

Light transmission

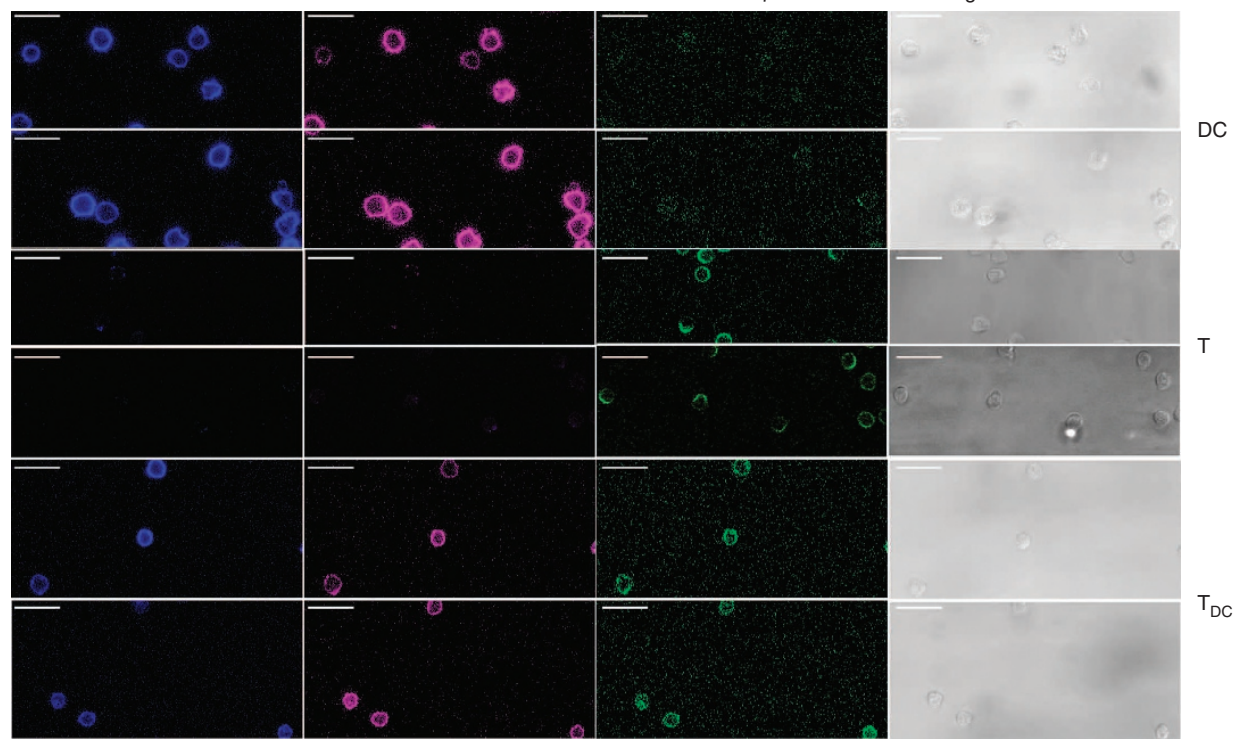

Figure 2 | $\mathbf{T}_{\mathrm{DC}}$ are single cells expressing $\mathbf{T}$ and DC molecules and expand in response to FLT3L. (a,c) Fluorescence reporter expression in splenocytes of CD11c-EGFP (a) or Thpok-GFP (c) reporter mice. (b) RT-PCR analysis of double-sorted cell subsets from B6 splenocytes. (d,e) B6 mice were injected subcutaneously in the back with B16 or B16-FLT3L melanoma cells. Ten to thirteen days after injection the indicated splenocyte subsets were analyzed for surface FLT3 levels (d) or frequency (e). The mean \pm s.e.m. of each subset from 2 (B16-injected) or 10 mice (wild type (WT) or B16-FLT3L) is shown in (e). Cells from uninjected mice are shown as a control (WT). (f) Confocal microscopy analysis of cells from double-sorted splenocytes of B16-FLT3L-injected mice. Scale bars, $20 \mu \mathrm{m}$. One representative experiment of at least three is shown in each panel.

these were genes encoding granzymes $A$ and $B$ and eomesodermin, proteins normally expressed in cytotoxic cells, such as $\mathrm{NK}$ and effector $\mathrm{CD}^{+}{ }^{+} \mathrm{T}$ cells. The relatively high expression of these genes in $\mathrm{T}_{\mathrm{DC}}$ was confirmed by RT-PCR, which revealed that Gzma was detectable only in $\mathrm{T}_{\mathrm{DC}}$, whereas Gzmb and Eomes were expressed in T cells but at lower levels than in $\mathrm{T}_{\mathrm{DC}}$ (Fig. 3b). Similar results were obtained with RT-PCR for Prf1, which encodes cytotoxic molecule perforin. Intracellular staining revealed that $\sim 20 \%$ of $\mathrm{CD}^{+} \mathrm{T}_{\mathrm{DC}}$ expressed granzyme $\mathrm{B}$ in the absence of stimulation, whereas although a small amount of mRNA was found by RT-PCR (Fig. 3b), the protein was undetectable in T cells (Fig. 3c). Therefore, in addition to sharing characteristics with $\mathrm{T}$ cells and $\mathrm{DCs}, \mathrm{T}_{\mathrm{DC}}$ exhibited a distinct molecular profile exemplified by cytotoxic gene expression. It is notable that $\mathrm{T}_{\mathrm{DC}}$ express a cytotoxic signature without signs of activation (Fig. 1g).
$T_{D C}$ require a thymus and positive selection for development. Conventional $\alpha \beta-\mathrm{T}$ cells require the thymus for development. Consistent with a similar requirement for $\mathrm{T}_{\mathrm{DC}}$, bone marrow cell cultures supplemented with granulocyte-monocyte-colonystimulating factor or FLT3L did not give rise to $\mathrm{T}_{\mathrm{DC}}$ (data not shown). In the thymus, a small percentage of cells expressing CD11c and MHC-II was found within both the CD $3^{\text {int }}$ and $C D 3^{\text {hi }}$ subsets (Fig. 4a). A requirement for $\mathrm{T}_{\mathrm{DC}}$ development in the thymus was confirmed by the observation that $T_{D C}$ were not detected in the spleens of athymic nude mice (Fig. 4b). To determine whether $\mathrm{T}_{\mathrm{DC}}$, such as $\alpha \beta$-T cells, undergo antigenspecific selection in the thymus, mice expressing $\alpha \beta$-TCR transgenes (Tg) on either positively selecting or non-selecting MHC haplotypes were studied. Rag2 $-1-$ AND TCR Tg thymocytes are positively selected on $\mathrm{H}-2^{\mathrm{b}}$ and $\mathrm{H}-2^{\mathrm{k}}$, but not the $\mathrm{H}-2^{\mathrm{q}}$ haplotype ${ }^{27,28}$. $\mathrm{T}$ and $\mathrm{T}_{\mathrm{DC}}$ were present in mice with positively 
a

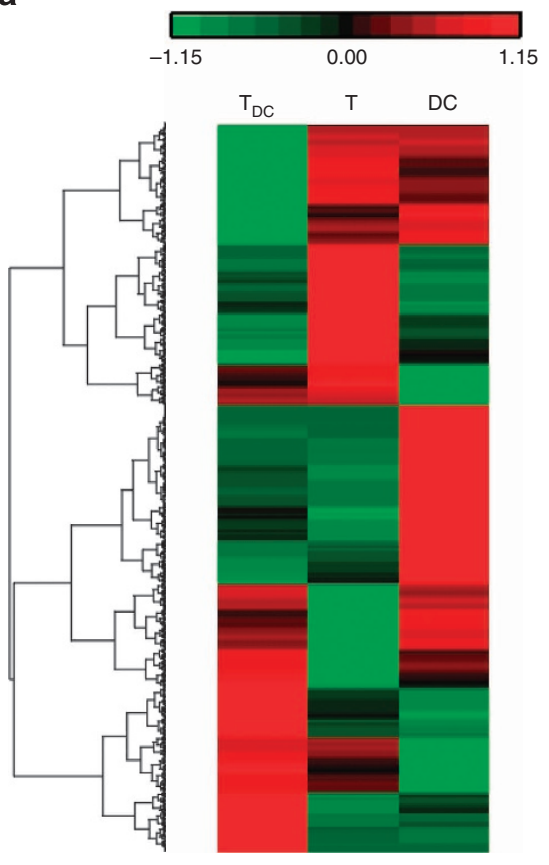

b

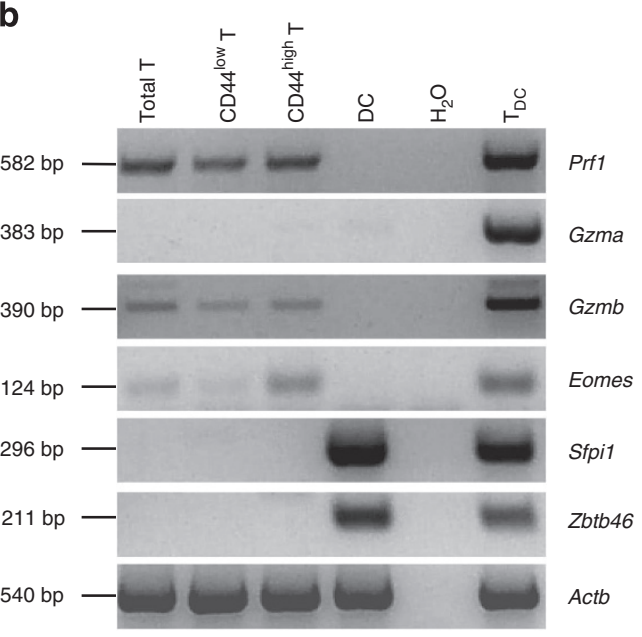

C
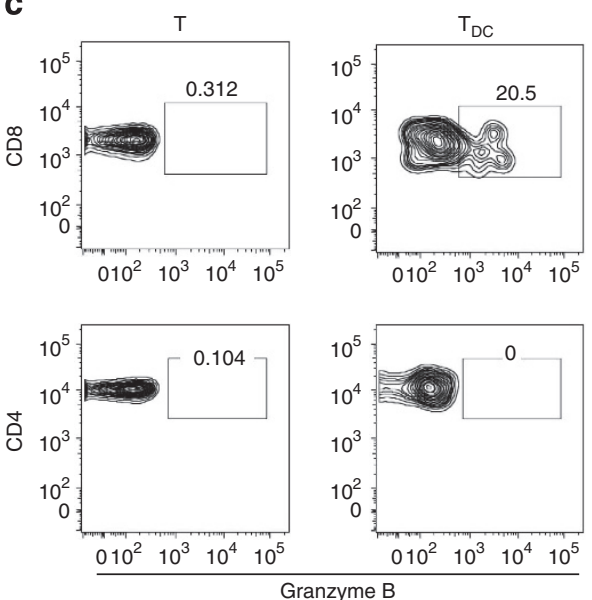

Figure 3 | Molecular profiling of $\mathbf{T}_{\mathbf{D C}}$ reveals a distinct genetic signature. (a) Gene expression heat map from microarray analysis of highly purified cells pooled from 12 B6 mice. Individual cell subsets are represented as columns. (b) RT-PCR of highly purified cells pooled from five B6 mice. One representative experiment of two to four independent analyses is shown. (c) Flow cytometric analysis of intracellular granzyme B in splenic Tor $T_{D C}$ from B6 mice.

Table 1 | Selected genes expressed by $T_{D C}$ and DCs represented as fold difference with respect to $T$ cells.

\begin{tabular}{ll} 
Gene symbol & Gene name \\
\hline Cd83 & CD83 antigen \\
Itgax & CD11c \\
$H 2-A b 1$ & Histocompatibility 2, class II antigen A, $\beta-1$ \\
$H 2-A a$ & Histocompatibility 2, class II antigen A, $\alpha$ \\
$H 2-A b 1$ & Histocompatibility 2, class II antigen A, $\beta-1$ \\
Cd74 & MHC class II-associated invariant chain \\
H2-Eb1 & Histocompatibility 2, class II antigen E $\beta$ \\
Flt3 & Fms-related tyrosine kinase 3 \\
Irf8 & Interferon regulatory factor 8 \\
Kit & Kit oncogene \\
Ccl3 & Chemokine (C-C motif) ligand 3 \\
II12b & IL-12b \\
Lyn & Tyrosine-protein kinase Lyn \\
Casp1 & Caspase-1 \\
Ifnar1 & IFN- $\alpha / \beta$ receptor 1 \\
Zbtb46 & Zinc finger and BTB domain containing 46 \\
Jun & Proto-oncogene c-Jun \\
II13ra1 & IL-13 receptor, $\alpha-1$ \\
TLR-13 & TLR-13 \\
Ciita & Class II transactivator
\end{tabular}

DC, dendritic cell; IFN, interferon; IL, interleukin; MHC, major histocompatibility complex; TLR, Toll-like receptor. 
selecting haplotypes but not in mice of the non-selecting $\mathrm{MHC}$, strongly suggesting that $\mathrm{T}_{\mathrm{DC}}$ require the same thymic-positive selection signals as conventional $\mathrm{T}$ cells (Fig. 4c). Additional evidence that $\mathrm{T}_{\mathrm{DC}}$ undergo positive selection came from studies Table 2 | Selected genes expressed by $T_{D C}$ and $T$ cells
represented as fold-difference with respect DCs.

\begin{tabular}{llcc} 
Gene symbol & Gene name & T & \\
\hline Lck $/ \mathbf{D C}$ & T/DC \\
Tcrb-J & Tyrosine-protein kinase Lck & 226 & 488 \\
Itk & TCR $\beta$, joining region & 229 & 366 \\
Cd3d & IL-2 inducible T-cell kinase & 210 & 323 \\
Cd247 & TCR T3 $\delta$ chain & 118 & 228 \\
Cd8b1 & TCR T3 $\zeta$ chain & 372 & 175 \\
Cd28 & CD8 antigen, $\beta$ chain 1 & 58 & 159 \\
Cd27 & CD28 antigen & 312 & 116 \\
Cd2 & CD27 antigen & 53 & 108 \\
Zap70 & T-cell surface antigen CD2 & 89 & 102 \\
Thy1 & Tyrosine-protein kinase ZAP-70 & 26 & 90 \\
Lat & Thymus cell antigen 1, $\theta$ & 58 & 89 \\
Cd3g & Linker for activation of T cells & 45 & 76 \\
II2rb & TCR T3 $\gamma$ chain & 357 & 72 \\
Tcra & IL-2 receptor, $\beta$ & 89 & 69 \\
Foxp3 & TCR $\alpha$ chain & 38 & 37 \\
Themis & Forkhead box P3 & 10 & 34 \\
Notch1 & Thymocyte selection associated & 10 & 24 \\
Ccnd2 & Notch gene homolog 1 & 8 & 23 \\
II7r & Cyclin D2 & 11 & 18 \\
\hline DC, dendritic cell; IL, interleukin; TCR, T-cell receptor. & 13 & 15 \\
\hline
\end{tabular}

of $\mathrm{T}_{\mathrm{DC}}$ Thpok expression, a transcription factor essential for CD4 expression in mature $\mathrm{T}$ cells. As seen in conventional $\mathrm{T}$ cells ${ }^{24}$, Thpok $^{-1-}$ mice lacked CD4 ${ }^{+} \mathrm{T}_{\mathrm{DC}}$, and $\mathrm{CD} 8^{+} \mathrm{T}_{\mathrm{DC}}$ frequency was increased (Fig. 4d). To formally demonstrate that CD4 lineage-selected $\mathrm{T}_{\mathrm{DC}}$ were not lost but redirected to the CD8 lineage, a GFP reporter that monitors Thpok promoter activity was used in Thpok-deficient mice ${ }^{24}$ to allow detection of CD4 lineage-selected $\mathrm{T}_{\mathrm{DC}}\left(\mathrm{CD}^{+} \mathrm{GFP}^{+}\right)$within the $\mathrm{CD} 8{ }^{+} \mathrm{T}_{\mathrm{DC}}$ population (Fig. 4e). Together, these findings demonstrate that $\mathrm{T}_{\mathrm{DC}}$ are similar to conventional $\mathrm{T}$ cells in their origin and development.

$T_{D C}$ have $T$-cell functional properties. The ability of $T_{D C}$ to respond to TCR-mediated stimulation was assessed by stimulating splenocytes with anti-CD3. After stimulation, $\mathrm{T}_{\mathrm{DC}}$ displayed high levels of the activation marker CD69 (Fig. 5a). TCR-mediated $\mathrm{T}$-cell proliferation requires stimulation via costimulatory receptors whose ligands are provided by APCs such as $\mathrm{DCs}^{29}$. Furthermore, stimulation with soluble anti-CD3 antibodies requires their immobilization by $A P C$ Fc receptors. As $T_{D C}$ exhibit DC characteristics and expressed CD80/CD86 (Supplementary Fig. 2a), we hypothesized that they might be able to provide these necessary functions for themselves. To test this, highly purified $\mathrm{T}$ cells or $\mathrm{T}_{\mathrm{DC}}$ were stimulated with soluble anti-CD3. In contrast to $\mathrm{T}$ cells alone, $\mathrm{T}_{\mathrm{DC}}$ expanded, and to a greater extent than $\mathrm{T}$ cells cocultured with DCs (Fig. 5b), indicating that they do not need help from conventional APC. Interestingly, whereas $\mathrm{T}_{\mathrm{DC}}$ activated via the TCR for up to $20 \mathrm{~h}$ retained their DC markers (data not shown), they lost them after proliferating (Supplementary Fig. 2b). To address the possibility that this might be due to expansion of a very small number of a

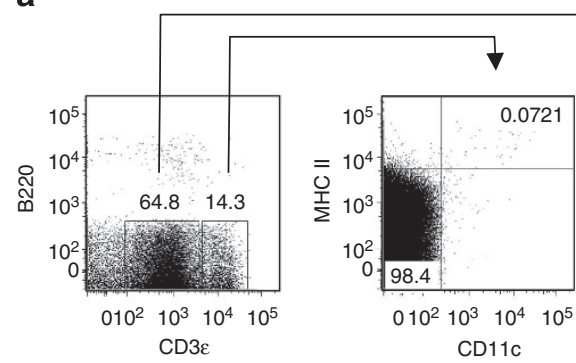

C

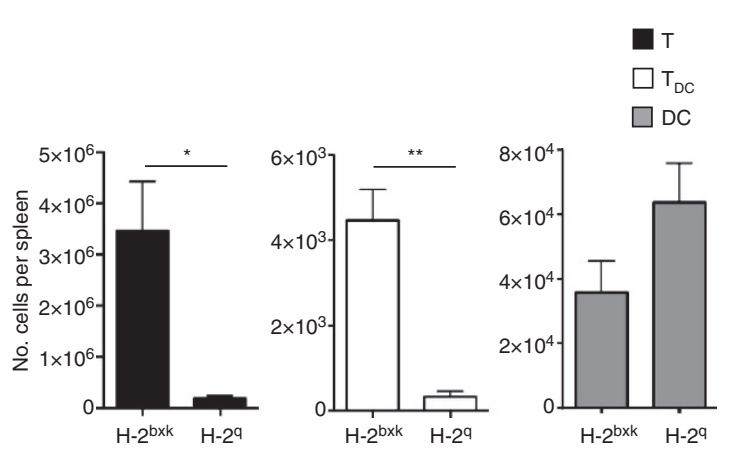

b

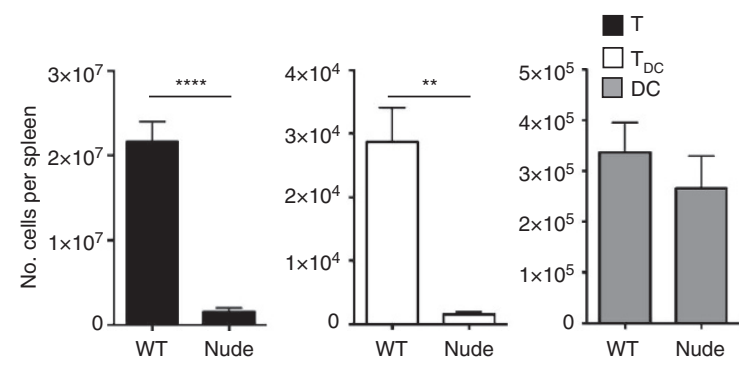

d

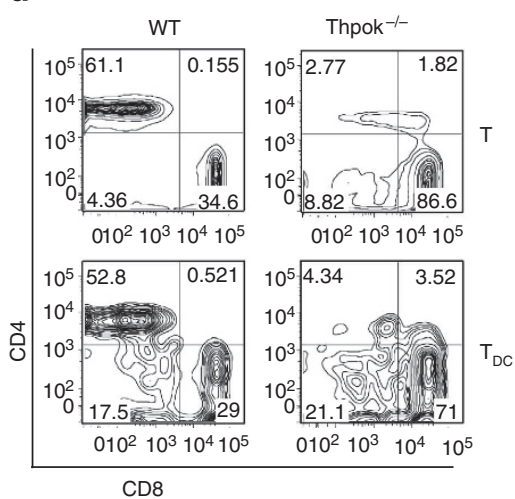

e Thpok-GFP transgene

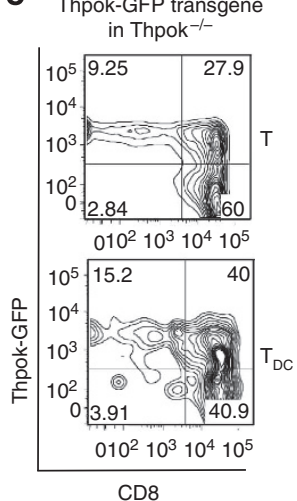

Figure 4 | $\mathbf{T}_{\mathbf{D C}}$ need a thymus and positive selection for development. (a) Gating strategy for identification of $T_{D C}$ in $B 6$ thymocytes. (b,c) Absolute numbers of the indicated cell subsets in spleens of athymic nude mice (b) or AND TCR Tg mice on H-2 ${ }^{\text {bxk }}$ or H-2 ${ }^{q}$ MHC haplotypes (c). Mean \pm s.e.m. of at least four mice per group, statistical analysis performed with a two-tailed Student's $t$-test. ${ }^{\star} P<0.05,{ }^{\star \star} P<0.01$, ${ }^{\star \star \star \star} P<0.001$. (d,e) Splenocytes of B6 wildtype (WT), Thpok ${ }^{-/}$(d) or Thpok ${ }^{-/-}$-Thpok-GFP mice (e) were analyzed for CD4, CD8 and GFP expression. 
a
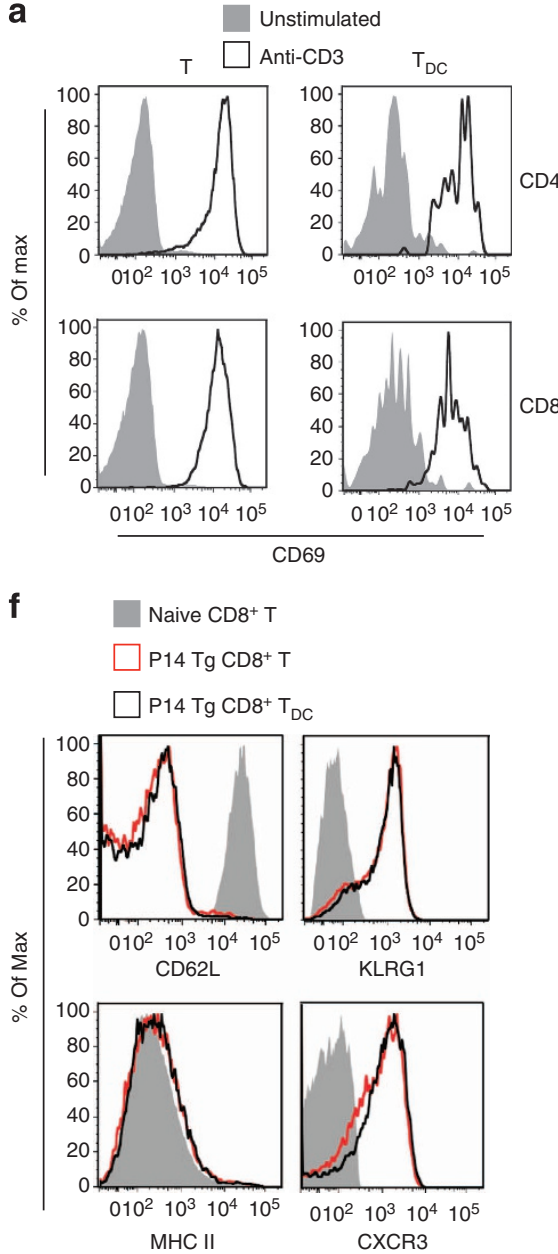

b

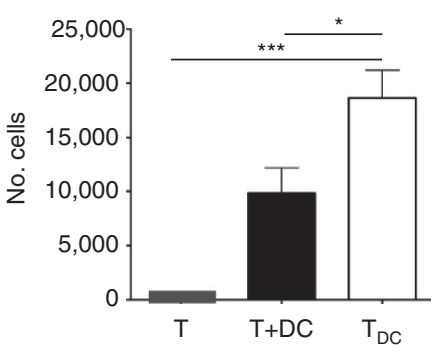

d

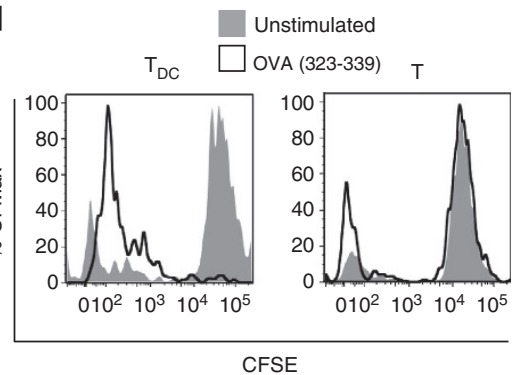

C

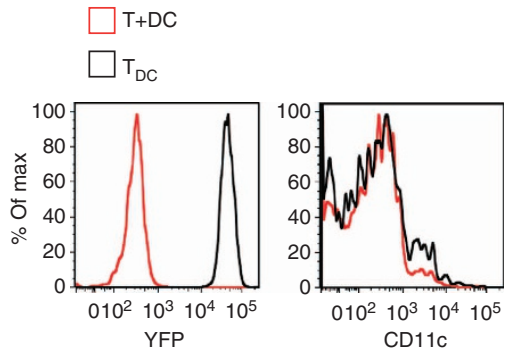

e
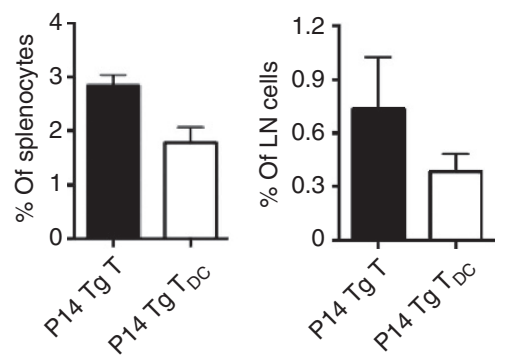

g
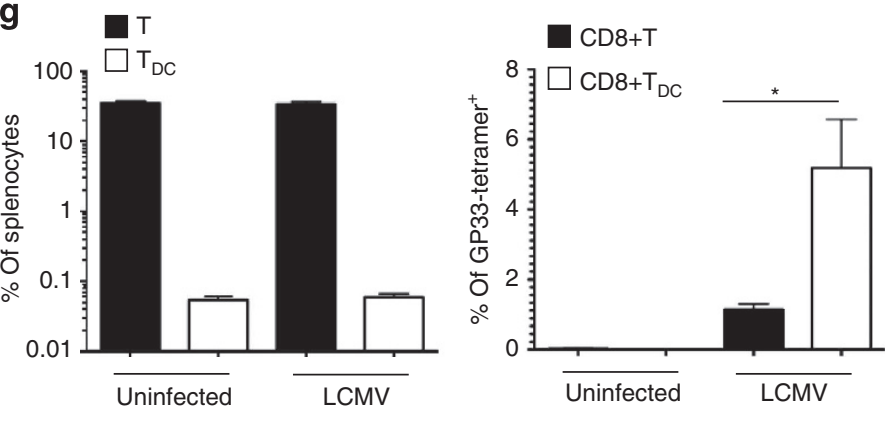

Figure 5 | T $\mathbf{D C}$ have T-cell functional properties. (a) Upregulation of CD69 on B6 splenocytes stimulated with soluble anti-CD3 for $18 \mathrm{~h}$. (b,c) Cell counts and YFP expression of $T_{D C}$ or T cells double-sorted from B6 (b) or Rosa26-CD11c-Cre-YFP (c) splenocytes, stimulated with soluble anti-CD3, supplemented with IL-2 on day 3 and analyzed on day 8 . Mean \pm s.e.m. of four independent experiments is shown in (b). (d) Carboxyfluorescein diacetate succinimidyl ester (CFSE) dilution of double-sorted $\mathrm{T}_{\mathrm{DC}}$ or T cells from OTII-Tg mice and stimulated with OVA 323-339 peptide (6.7 $\left.\mu \mathrm{M}\right)$ for 7 days. (e) Frequency and surface markers (f) of double-sorted P14 TCR Tg T DC or T cells adoptively transferred at a 1:1 ratio into B6 mice, infected the next day with LCMV Armstrong and analysed 8 days later. Mean \pm s.e.m. of three independent experiments is shown in $(\mathbf{e}, \mathbf{g})$. Frequency of the indicated cell subsets from B6 mice infected with LCMV Armstrong strain 2 months earlier. Mean \pm s.e.m. of six mice is shown, and a two-tailed Student's $t$-test was performed. ${ }^{\star} P<0.05$, ${ }^{\star \star \star} P<0.005$

contaminating conventional $\mathrm{T}$ cells, we crossed Rosa26-YFP mice, which express fluorescent YFP only if a stop codon between the Rosa26 promoter and YFP is excised by $\mathrm{Cre}^{30}$, with CD11cCre-expressing animals. YFP expression was observed in the majority of DCs and $\mathrm{T}_{\mathrm{DC}}$, and YFP ${ }^{\text {bright }}$ cells were isolated by sorting (Supplementary Fig. 2c) and stimulated with soluble antiCD3 (Fig. 5c). $\mathrm{T}_{\mathrm{DC}}$ expanded in culture and lost cell surface CD11c but maintained YFP expression. Importantly, YFP was not acquired by conventional $T$ cells expanded in the presence of DCs. Thus, $\mathrm{T}_{\mathrm{DC}}$ expand in response to TCRmediated stimulation. The question of whether $\mathrm{T}_{\mathrm{DC}}$ respond to cognate antigen was addressed with $\alpha \beta$-TCR Tg mice, all of which that we examined had $\mathrm{T}_{\mathrm{DC}}$ (Supplementary Fig. $2 \mathrm{~d}$ ). $\mathrm{T}_{\mathrm{DC}}$ sorted from OTII-Tg mice and stimulated with cognate antigen (chicken ovalbumin (OVA) peptide 323-329) proliferated in the absence of any additional APC, whereas conventional T cells did not (Fig. 5d). Thus, $\mathrm{T}_{\mathrm{DC}}$ have a functional TCR and are self-sufficient for antigen presentation.

To assess $\mathrm{T}_{\mathrm{DC}}$ responses in vivo, equal numbers of lymphocytic choriomeningitis virus (LCMV) glycoprotein (gp)33-41-specific $\mathrm{P} 14 \mathrm{Tg} \mathrm{T}_{\mathrm{DC}}$ and conventional $\mathrm{T}$ cells were adoptively transferred into wild-type hosts, which were then infected with LCMV. $\mathrm{T}_{\mathrm{DC}}$ and T-cell expansion was similar at day 8 , the peak of the response (Fig. 5e). Moreover, comparable to the transferred $\mathrm{T}$ cells, all $\mathrm{T}_{\mathrm{DC}}$ had an activated phenotype: CD62L $\mathrm{L}^{\text {lo }}, \mathrm{KLRG}{ }^{\text {hi }}$ and $\mathrm{CXCR}^{\text {hi }}$ (Fig. 5f). Interestingly, $\mathrm{T}_{\mathrm{DC}}$ lost expression of MHC-II, acquiring a conventional T-cell phenotype after LCMVmediated expansion, as had been seen after proliferation in vitro. Analysis 2 months after LCMV infection, when numbers of both $\mathrm{T}$ and $\mathrm{T}_{\mathrm{DC}}$ are at steady-state levels (Fig. 5g, left), found gp33 tetramer ${ }^{+}$, and therefore antigen-experienced, $\mathrm{T}_{\mathrm{DC}}$ that presumably had re-acquired MHC-II (Fig. 5g, right). Notably, a relatively high percentage of $\mathrm{T}_{\mathrm{DC}}$ were gp33-tetramer-positive, indicating that memory $\mathrm{T}_{\mathrm{DC}}$ persist in vivo like conventional memory T cells.

$T_{D C}$ respond to TLR agonists in a DC-like manner. The innate characteristics of $\mathrm{T}_{\mathrm{DC}}$ were explored. Unlike $\mathrm{T}$ cells, DCs require signaling via FLT3 for development and maintenance ${ }^{9}$. Notably, the fraction of $\mathrm{T}_{\mathrm{DC}}$ was markedly reduced in mice lacking the ligand for FLT3, FLT3L, to an extent similar to DCs (Fig. 6a). 
To test the ability of $\mathrm{T}_{\mathrm{DC}}$ to respond like innate immune cells, total splenocytes were stimulated with lipopolysaccharide (LPS) (Fig. 6b) or other TLR agonists (Supplementary Fig. 3a). $\mathrm{T}_{\mathrm{DC}}$ upregulated costimulatory molecules in a manner remarkably similar to DCs (Fig. 6b), whereas no upregulation was observed for conventional $\mathrm{T}$ cells (data not shown). In addition, $\mathrm{T}_{\mathrm{DC}}$
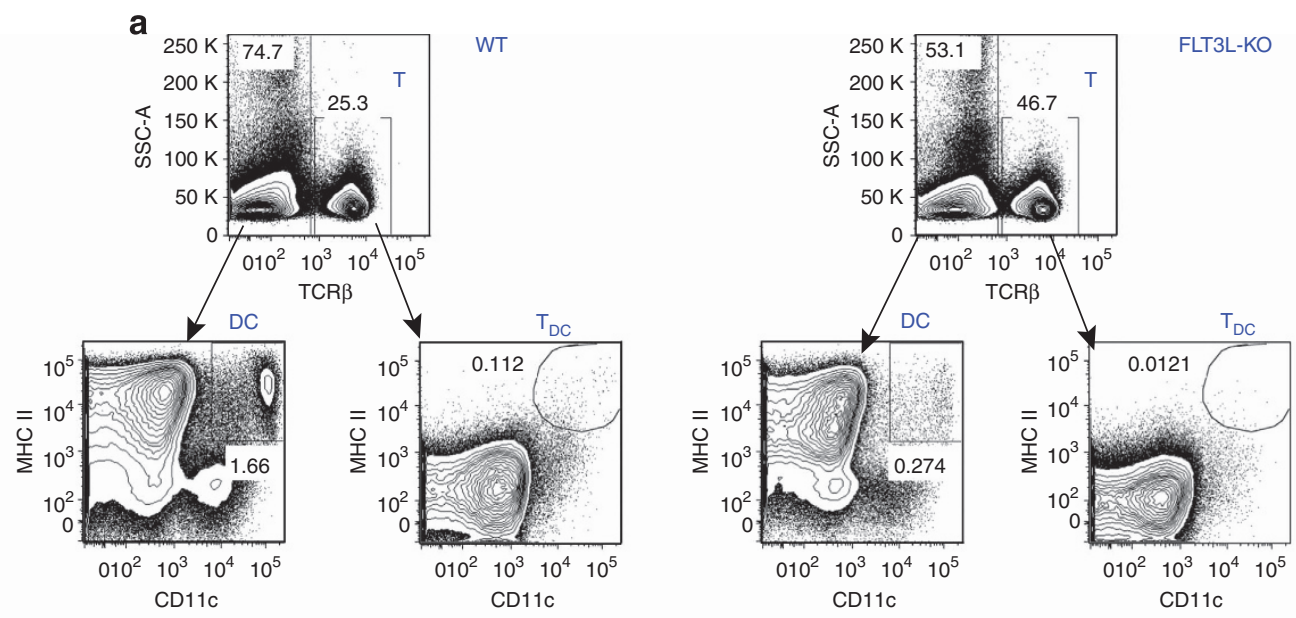
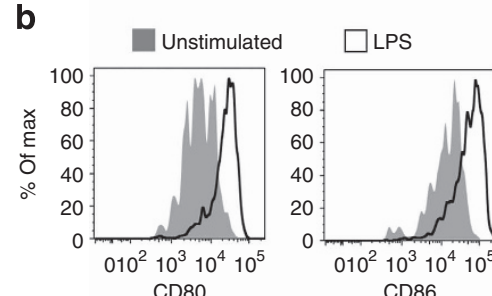

CD86
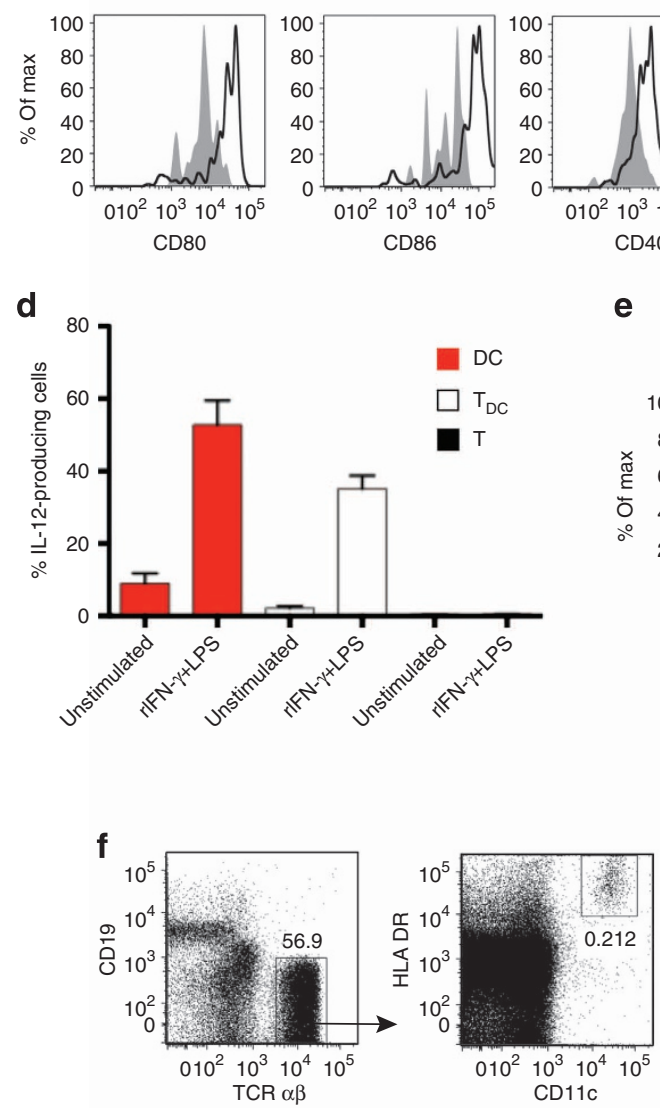

e

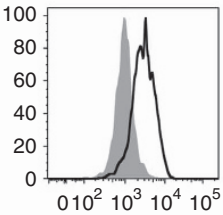

CD40

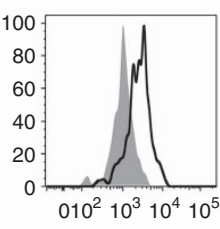

CD40

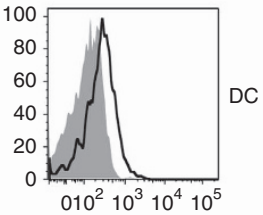

CD70

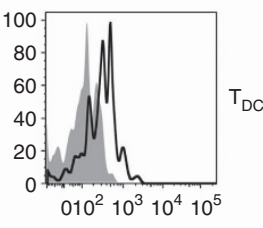

CD70

C

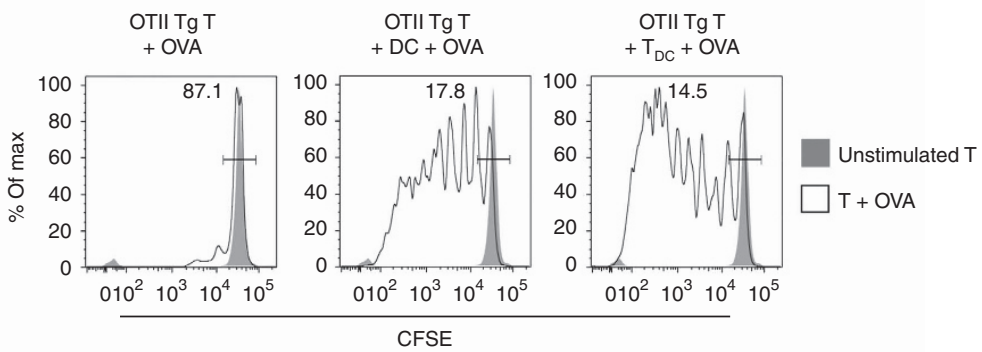

g

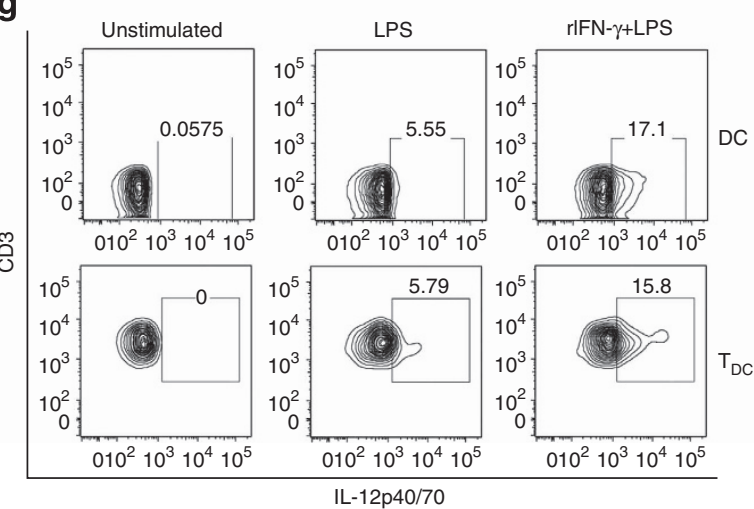


stimulated with TLR agonists produced IL-12, a cytokine produced by DCs and important for Th1 polarization (Supplementary Fig. 3b). IL-12 production by $\mathrm{T}_{\mathrm{DC}}$ was even more notable when splenocytes were primed with recombinant interferon- $\gamma(\mathrm{rIFN}-\gamma)$ followed by LPS stimulation (Fig. 6c,d). A prominent characteristic of DCs is their ability to process and present antigens on MHC-II. Purified $\mathrm{T}_{\mathrm{DC}}$ or DCs were co-cultured with OTII Tg T cells in the presence of whole-OVA protein. $\mathrm{T}_{\mathrm{DC}}$-induced antigen-specific $\mathrm{T}$-cell proliferation similar to DCs (Fig. 6e), indicating that $\mathrm{T}_{\mathrm{DC}}$ can process as well as present antigen on MHC-II. Thus, $\mathrm{T}_{\mathrm{DC}}$ have functional properties characteristic of bona fide innate cells.

To determine whether $\mathrm{T}_{\mathrm{DC}}$ exist in humans, peripheral blood lymphocytes from uninfected donors were analyzed. Approximately $0.2 \%$ of $\mathrm{CD} 3^{+} \mathrm{TCR} \alpha \beta^{+}$cells were positive for CD11c and human leukocyte antigen-DR (MHC-II), but unlike murine $\mathrm{T}_{\mathrm{DC}}$ the levels of these molecules were similar to those on cDCs (Fig. $6 \mathrm{f}$ and Supplementary Fig. 3c). Human $\mathrm{T}_{\mathrm{DC}}$ expressed $\mathrm{T}$-cell markers at the same levels as conventional $\mathrm{T}$ cells, and like their murine counterparts, were single positive for CD4 or CD8 (Supplementary Fig. 3d). As activated human $\mathrm{CD} 4{ }^{+} \mathrm{T}$ cells expressing MHC-II have been described ${ }^{31}$, we asked whether human $\mathrm{T}_{\mathrm{DC}}$ behave like innate immune cells. Human $\mathrm{T}_{\mathrm{DC}}$ stimulated with LPS produced IL-12 (Fig. 6g). Treatment with rIFN- $\gamma$ before LPS stimulation increased IL-12 production by $\mathrm{T}_{\mathrm{DC}}$, as it did for DCs.

\section{Discussion}

Here, we report the identification of $\mathrm{T}_{\mathrm{DC}}$, a subset of cells characterized by the coexistence of features of conventional polyclonal T cells and DCs. Similar to another rare but notable DC subset, plasmacytoid DC, $\mathrm{T}_{\mathrm{DC}}$ have lymphocyte-like rather than DC morphology and express intermediate levels of CD11c and MHC-II (ref. 32). The fact that $\mathrm{T}_{\mathrm{DC}}$ recombine and express a functional TCR, but also have the ability to respond to TLR stimuli in a rapid, DC-like manner places $\mathrm{T}_{\mathrm{DC}}$ in the heterogeneous category of 'innate $\mathrm{T}$ cells'. However, $\mathrm{T}_{\mathrm{DC}}$ substantially differ from other innate $\mathrm{T}$ cells primarily due to antigen-specific selection processes indistinguishable from classical $\alpha \beta$ cells and the ability to mount a full-scale proliferative response to cognate antigens, both of which are essential in adaptive immunity. Moreover, they are negative for CD122, CD69 and CD25, markers constitutively expressed by NKT cells, and do not express NK lineage markers such as NK1.1 (refs 16,33,34).

It is generally thought that cDCs and T cells originate from different precursors and pursue unrelated developmental programs ${ }^{4,11}$. The identification of $\mathrm{T}_{\mathrm{DC}}$, which express lineagespecific markers of both DCs (PU.1 and Zbtb46) and T cells (TCR $\alpha \beta$ ), suggests that the lymphoid and myeloid differentiation pathways are not mutually exclusive, as previously thought. Whereas DN2 thymocytes, before T-cell commitment, retain the potential to generate both myeloid and NK progeny ${ }^{14}$, a mature cell seemingly committed to both $\mathrm{T}$ and DC lineages, with the capacity to respond in either a T- or DC-like manner, has not been described. If anything, myeloid and T-cell commitment are generally thought to be mutually exclusive. For example, forced expression of PU.1 at the DN3 stage inhibits T-cell development, strongly arguing for its role in terminating $\mathrm{T}$-cell lineage commitment $^{35}$. It is noteworthy, however, that signaling through Notch, initially thought to exclusively promote T-cell lineage commitment, can also promote the development of Thy $1^{+}$DCs in bone marrow cultures ${ }^{36}$ and the differentiation of some DC subsets in the periphery ${ }^{37}$. Such findings could perhaps explain how some cell types might escape what was thought to be a rule for $\mathrm{T}$-cell lineage commitment.

cDNA microarray analysis revealed that $\mathrm{T}_{\mathrm{DC}}$ expressed a number of genes that were not found in DCs or $\mathrm{T}$ cells. This distinct genetic profile identifies them as a separate cell type and raises the possibility that $\mathrm{T}_{\mathrm{DC}}$ may have functions other than those of these two cell types. In particular, $\mathrm{T}_{\mathrm{DC}}$ express granzymes and perforin at very high levels in the absence of signs of activation, which to our knowledge makes them the first naive polyclonal $\mathrm{T}$ cells with cytotoxic features to have been described thus far. Notably, only $\mathrm{T}_{\mathrm{DC}}$, and not $\mathrm{T}$ cells or $\mathrm{DCs}$ from naïve mice, expressed mRNA for granzyme $\mathrm{A}$, a protease with unique properties such as being able to activate alternative death pathways ${ }^{38,39}$. A recent paper reports that a subset of murine immature DC deletes cognate $\mathrm{CD}^{+} \mathrm{T}$ cells through a mechanism mediated by perforin and granzyme $\mathrm{A}^{40}$. This raises the speculation that $\mathrm{T}_{\mathrm{DC}}$ might as well use their cytotoxic machinery to control an exacerbated immune response.

The physiological role of $\mathrm{T}_{\mathrm{DC}}$ is currently being investigated by genetic approaches. Based on the fact that $\mathrm{T}_{\mathrm{DC}}$ combine features and functions of T cells and DCs, it is tempting to speculate that such duality might render $\mathrm{T}_{\mathrm{DC}}$ particularly responsive to infectious organisms, because they can bridge innate and adaptive traits. The contribution of $\mathrm{T}_{\mathrm{DC}}$ would be masked because, on TCR-mediated proliferation, $\mathrm{T}_{\mathrm{DC}}$ transiently lose DC markers, becoming indistinguishable from conventional $\mathrm{T}$ cells. However, as shown in responses to $\mathrm{LCMV}$, antigen-experienced $\mathrm{T}_{\mathrm{DC}}$ re-acquire DC markers over time, suggesting long-term stability of their 'mixed' lineage.

Infectious diseases are not the only context where $\mathrm{T}_{\mathrm{DC}}$ might have a role. To our knowledge, $\mathrm{T}_{\mathrm{DC}}$ are the first instance of an $\alpha \beta-T$ cell that produces IL-12. Several reports show that tumorspecific $\mathrm{T}$ cells engineered to produce IL-12 are very effective in eliciting regression of, or even eradicating, melanomas ${ }^{41-43}$. One could envision that tumor-specific $\mathrm{T}_{\mathrm{DC}}$ might be effective in this setting because they produce IL-12 on stimulation, similar to innate APC. Thus, $\mathrm{T}_{\mathrm{DC}}$, present in mice and humans, comprise a new and intriguing cell subset poised at the intersection of innate and adaptive immunity.

\section{Methods}

Mice. C57BL/6 (B6) and athymic nude mice were obtained from the NCI Frederick Animal Facility. FLT3L-deficient mice were generated by Immunex as described $^{16}$ and purchased from Taconic. CD11c-Cre, CD11c-Cre-EGFP, ROSA2 $6^{\text {flox }}$ STOP ${ }^{\text {flox }}$ YFP, OTII TCR Tg, AND TCR Tg, and B6 mice-bearing CD45.1 or Thy-1.1 congenic markers were obtained from The Jackson Laboratory. Rosa26-CD11c-cre-YFP mice were obtained by breeding ROSA26 ${ }^{\text {flox }}$ STOP ${ }^{\text {flox}}$ YFP to CD11c-Cre mice. Thpok-GFP, Thpok ${ }^{-1-}$ and P14 TCR Tg in B6 background

Figure 6 | $\mathbf{T}_{\mathbf{D C}}$ have DC properties and can be detected in human blood. (a) The indicated cell subsets from wild-type (WT) and FLT3L-deficient mice were stained and analyzed. One representative experiment of two is shown. (b) Flow cytometric analysis of surface costimulatory molecules in B6-gated splenic $T_{D C}$ stimulated with LPS $\left(100 \mathrm{ng} \mathrm{ml}^{-1}\right)$ for $24 \mathrm{~h}$. (c-d) Representative experiment (c) or mean \pm s.e.m. of three mice (d) depicting IL-12 production by splenocytes of $\mathrm{B} 6$ mice primed with rIFN- $\gamma\left(50 \mathrm{ng} \mathrm{ml}^{-1}\right)$ and stimulated with LPS $\left(200 \mathrm{ng} \mathrm{ml}^{-1}\right)$ for $18 \mathrm{~h}$. (e) Carboxyfluorescein diacetate succinimidyl ester (CFSE) dilution in $>99 \%$ pure OTII Tg T cells co-cultured with double-sorted $\mathrm{T}_{\mathrm{DC}}$ or DCs stimulated with whole-OVA protein (50 $\mu \mathrm{g} \mathrm{ml}^{-1}$ ). (f) Gating strategy for identification of $T_{D C}$ from human peripheral blood mononuclear cells. (g) Intracellular IL-12 production by human $T_{D C}$ stimulated with LPS $\left(200 \mathrm{ng} \mathrm{ml}^{-1}\right)$ for $24 \mathrm{~h}$ in the presence or absence of recombinant $\mathrm{rlFN}-\gamma\left(50 \mathrm{ng} \mathrm{ml}^{-1}\right)$. One representative experiment of three is shown. 
mice were a kind gift of Dr Rémy Bosselut (NCI). The Animal Care and Use Committee of the National Cancer Institute approved all animal experimental procedures.

Cells and reagents. Purified or fluorochrome-conjugated antibodies to murine and human cell surface markers and cytokines were purchased from $\mathrm{BD}$ Biosciences or eBioscience. LCMV Armstrong strain was a gift from Dr Rafi Ahmed (Emory University School of Medicine). The H-2D ${ }^{\mathrm{b}} / \mathrm{LCMV}$ gp33-41 (KAVYNFATC) tetramer labeled with allophycocyanin was obtained from the NIH Tetramer Core Facility at Emory University.

LPS, brefeldin A and OVA were purchased from Sigma Aldrich, PolyI:C and Pam3CSK4 obtained from Invivogen, OVA 323-339 peptide obtained from Genscript, carboxyfluorescein diacetate succinimidyl ester obtained from Invitrogen and recombinant IL-2 and IFN- $\gamma$ obtained from eBioscience. B16-FLT3L murine melanoma cells were a gift from Ulrich H. von Andrian (Harvard Medical School).

B16-FLT3L-induced cell expansion in vivo. B16-FLT3L cells were cultured in DMEM containing $10 \%$ fetal calf serum and antibiotics. Mice were injected subcutaneously with $10^{6}$ B16-FLT3L cells and lymphoid cells were analyzed 10-13 days later.

Cell preparation. Thymus, spleen and lymph nodes were collected and total cell suspensions made by gently mashing the debris through $40-\mu \mathrm{M}$ nylon mesh (BD Biosciences). Viable cells were counted by Trypan Blue exclusion, and the distribution of lymphoid populations in each organ was determined by cell surface staining and flow cytometry (LSRII, BD Biosciences). In some experiments, the indicated subsets underwent two or three rounds of sequential sorting to a purity of $\geq 99 \%$ (FACSAria I Cell Sorter obtained from BD Biosciences). Peripheral blood mononuclear cells from healthy donors were isolated from buffy coats of healthy donors using a Ficoll gradient (Ficoll-Paque PLUS obtained from GE Healthcare).

Confocal microscopy. Splenocytes were stained with antibodies to CD11c, MHC-II and TCR $\beta$ (H57), sorted to $>99 \%$ purity and analyzed by confocal microscopy. Confocal images were sequentially acquired with Zeiss ZEN 2009 software on a Zeiss LSM 710 NLO Confocal system (Carl Zeiss Inc., Thornwood, NY, USA) with a Zeiss Observer Z1 inverted microscope and diode laser tuned to $405 \mathrm{~nm}$, a $25-\mathrm{mW}$ Argon visible laser tuned to $488 \mathrm{~nm}$ and a HeNe laser tuned to $633 \mathrm{~nm}$. A 63X Plan-Apochromat 1.4 NA oil immersion objective was used and digital images were $512 \times 512$ pixels with $0.264-\mathrm{mm}$ pixel size. Emission signals after sequential excitation of eFluor450, FITC and APC by the 405-nm, 488-nm or 633-nm laser lines were collected with a BP 419-485-nm filter, BP 495-534-nm filter and BP 650-710-nm filter, respectively, using individual photomultipliers.

Cell culture and stimulation. Cultures were performed with RPMI 1640 (Gibco) supplemented with $10 \%$ heat-inactivated fetal calf serum, glutamine, $\beta$-mercaptoethanol and antibiotics. Murine splenocytes or human peripheral blood mononuclear cells were stimulated with TLR agonists or with soluble anti-CD3E (2C11) at the indicated concentrations. Activation markers were detected by surface staining 18-24 h later. In some experiments, brefeldin A (Sigma Aldrich) was added at a concentration of $10 \mu \mathrm{g} \mathrm{ml}^{-1} 2 \mathrm{~h}$ after stimulation and after another $16-24 \mathrm{~h}$ cells were fixed and permeabilized (BD Cytofix/Cytoperm and Perm/Wash Buffer kit) and stained for IL-12. In some proliferation experiments, double-sorted cells were stimulated with soluble anti-CD3 $\left(1 \mu \mathrm{g} \mathrm{ml}^{-1}\right)$ and at day 3 the cultures were supplemented with IL-2 $\left(20 \mathrm{U} \mathrm{ml}^{-1}\right)$ for 5 more days. When indicated, sorted cells were labeled with carboxyfluorescein diacetate succinimidyl ester $(0.5 \mu \mathrm{M})$ and stimulated with OVA peptide $323-339$ or whole protein at the indicated concentrations.

\section{Adoptive transfers and LCMV infection. P14 TCR Tg T cells from CD45.1} mice or P14 TCR Tg $\mathrm{T}_{\mathrm{DC}}$ from Thy1.1 ${ }^{+}$mice were sorted, mixed 1:1 (5,000 cells total) and injected intravenous into B6 recipients. The day after adoptive transfer, mice were infected intraperitoneal with $2 \times 10^{5}$ plaque-forming units of LCMV Armstrong strain, and spleen and lymph node cells were analyzed 8 days later. In other experiments, endogenous responses to LCMV were determined by infecting B6 mice with LCMV Armstrong strain and analyzed 2 months later.

Microarray analysis and RT-PCR. Total RNA was isolated with the RNeasy Micro kit (Qiagen) from 1,000 to 4,000 cells that were double or triple sorted from B6 splenocytes. Microarray gene expression was performed by the Laboratory of Molecular Technology (NCI), with Affymetrix 4302.0 GeneChip technology after RNA was amplified with a NuGEN WT-Ovation kit (Nugen). Microarray data analysis was performed with Partek Genomics Suite 6.6 (St Louis, MO, USA). One-way analysis of variance was applied to three samples with paired comparisons between samples $\left(T_{D C}\right.$ versus $T$ cells, $T_{D C}$ versus $D C s$ and $D C s$ versus T cells). For Ciita detection by RT-PCR, cDNA was synthesized using the SuperScriptTM II RT kit (Invitrogen) and RT-PCR was performed with Ciita primers
(5'-CCAAAGGATGTGGAAGACCT- $3^{\prime}$ and $5^{\prime}$-AGCTTCTTAAGGTCCCGG AT- $\left.3^{\prime}\right)$ and $H$ prt primers ( $5^{\prime}$-AAACAATGCAAACTTTGCTTTCC- $3^{\prime}$ and $5^{\prime}$-TCCTTTTCACCAGCAAGCTTG- $3^{\prime}$ ). For the other genes SuperScript III One-Step RT-PCR System with Platinum Taq High Fidelity kit (Invitrogen) was used with gene-specific primers to retro-transcribe and amplify trancripts in one step. We used the following primer pairs: Eomes (5'-TCGTGGAAGTGACAG AGGAC- $3^{\prime}$ and $5^{\prime}$-AGCTGGGTGATATCCGTGTT- $3^{\prime}$ ), Gzma (5'-AGGCTGTGA AAGAATCATTGGAG- ${ }^{\prime}$ and $5^{\prime}$-ATCCTGCTACTCGGCATCTGGTTC- $3^{\prime}$ ), Gzmb (5'-ACTTTCGATCAAGGATCAGCA-3' and $5^{\prime}$-ACTGTCAGCTCAACCT CTTGT- $\left.3^{\prime}\right)$, Prf 1 ( $5^{\prime}$-CAAGCAGAAGCACAAGTTCGT- $3^{\prime}$ and $5^{\prime}$-GTGATAA AGTGCGTGCCATA- $\left.3^{\prime}\right)$, Actb (5'-GTGGGCCGCCCTAGGCACC- $3^{\prime}$ and $5^{\prime}$-TCTTTGATGTCACGCACGAT-3'), Sfpil (5'-TCCATCGGATGACTTGG TTA- $3^{\prime}$ and $5^{\prime}$-AGGAAACCTGGTGACTGAGG- $\left.3^{\prime}\right), Z b t b 46$ (5'-CCACTCACTGT CTCTGAACGA- $3^{\prime}$ and $5^{\prime}$-CTTCTTGTCCTTGCTGTGGA-3').

\section{References}

1. Moser, M. \& Leo, O. Key concepts in immunology. Vaccine 28(Suppl 3): C2-13 (2010).

2. Banchereau, J. \& Steinman, R. M. Dendritic cells and the control of immunity. Nature 392, 245-252 (1998).

3. Kawai, T. \& Akira, S. The role of pattern-recognition receptors in innate immunity: update on Toll-like receptors. Nat. Immunol. 11, 373-384 (2010).

4. Liu, K. \& Nussenzweig, M. C. Origin and development of dendritic cells. Immunol. Rev. 234, 45-54 (2010).

5. Mak, K. S., Funnell, A. P., Pearson, R. C. \& Crossley, M PU.1 and haematopoietic cell fate: dosage matters. Int. J. Cell Biol. 2011, 808524 (2011)

6. Satpathy, A. T., Murphy, K. M. \& Kc, W. Transcription factor networks in dendritic cell development. Semin. Immunol. 23, 388-397 (2011).

7. Meredith, M. M. et al. Expression of the zinc finger transcription factor $\mathrm{zDC}$ (Zbtb46, Btbd4) defines the classical dendritic cell lineage. J. Exp. Med. 209, 1153-1165 (2012).

8. Satpathy, A. T. et al. Zbtb46 expression distinguishes classical dendritic cells and their committed progenitors from other immune lineages. J. Exp. Med. 209, 1135-1152 (2012).

9. McKenna, H. J. et al. Mice lacking flt3 ligand have deficient hematopoiesis affecting hematopoietic progenitor cells, dendritic cells, and natural killer cells. Blood 95, 3489-3497 (2000).

10. Love, P. E. \& Bhandoola, A. Signal integration and crosstalk during thymocyte migration and emigration. Nat. Rev. Immunol. 11, 469-477 (2011).

11. Yang, Q., Jeremiah Bell, J. \& Bhandoola, A T-cell lineage determination. Immunol. Rev. 238, 12-22 (2010).

12. Masuda, K. et al. T cell lineage determination precedes the initiation of TCR beta gene rearrangement. J. Immunol. 179, 3699-3706 (2007).

13. Moore, A. J. et al. Transcriptional priming of intrathymic precursors for dendritic cell development. Development 139, 373-384 (2012).

14. Yui, M. A., Feng, N. \& Rothenberg, E. V. Fine-scale staging of T cell lineage commitment in adult mouse thymus. J. Immunol. 185, 284-293 (2010).

15. Wu, L. \& Van Kaer, L. Natural killer T cells in health and disease. Front. Biosci. 3, 236-251 (2011).

16. Bonneville, M., O’Brien, R. L. \& Born, W. K. Gammadelta T cell effector functions: a blend of innate programming and acquired plasticity. Nat. Rev. Immunol. 10, 467-478 (2010).

17. Kabelitz, D. Expression and function of Toll-like receptors in T lymphocytes. Curr. Opin. Immunol. 19, 39-45 (2007).

18. Komai-Koma, M., Jones, L., Ogg, G. S., Xu, D. \& Liew, F. Y. TLR2 is expressed on activated T cells as a costimulatory receptor. Proc. Natl Acad. Sci. USA. 101, 3029-3034 (2004).

19. Beyer, M. et al. The beta2 integrin CD11c distinguishes a subset of cytotoxic pulmonary $\mathrm{T}$ cells with potent antiviral effects in vitro and in vivo. Respir. Res. 6, 70 (2005).

20. Huleatt, J. W. \& Lefrancois, L. Antigen-driven induction of CD11c on intestinal intraepithelial lymphocytes and CD8 $+\mathrm{T}$ cells in vivo. J. Immunol. 154, 5684-5693 (1995).

21. Lin, Y., Roberts, T. J., Sriram, V., Cho, S. \& Brutkiewicz, R. R. Myeloid marker expression on antiviral CD8 $+\mathrm{T}$ cells following an acute virus infection. Eur. J. Immunol. 33, 2736-2743 (2003).

22. Rechavi, O., Goldstein, I. \& Kloog, Y. Intercellular exchange of proteins: the immune cell habit of sharing. FEBS Lett. 583, 1792-1799 (2009).

23. Schooten, E., Klous, P., van den Elsen, P. J. \& Holling, T. M. Lack of MHC-II expression in activated mouse $\mathrm{T}$ cells correlates with DNA methylation at the CIITA-PIII region. Immunogenetics 57, 795-799 (2005).

24. Wang, L. et al. Distinct functions for the transcription factors GATA-3 and ThPOK during intrathymic differentiation of CD4 $(+)$ T cells. Nat. Immunol 9, 1122-1130 (2008).

25. Mach, N. et al. Differences in dendritic cells stimulated in vivo by tumors engineered to secrete granulocyte-macrophage colony-stimulating factor or Flt3-ligand. Cancer Res. 60, 3239-3246 (2000). 
26. Waskow, C. et al. The receptor tyrosine kinase Flt3 is required for dendritic cell development in peripheral lymphoid tissues. Nat. Immunol. 9, 676-683 (2008).

27. Kaye, J., Vasquez, N. J. \& Hedrick, S. M. Involvement of the same region of the $\mathrm{T}$ cell antigen receptor in thymic selection and foreign peptide recognition. J. Immunol. 148, 3342-3353 (1992).

28. Matechak, E. O., Killeen, N., Hedrick, S. M. \& Fowlkes, B. J. MHC class II-specific T cells can develop in the CD8 lineage when CD4 is absent. Immunity 4, 337-347 (1996).

29. Smith-Garvin, J. E., Koretzky, G. A. \& Jordan, M. S. T cell activation. Annu. Rev. Immunol. 27, 591-619 (2009).

30. Srinivas, S. et al. Cre reporter strains produced by targeted insertion of EYFP and ECFP into the ROSA26 locus. BMC Dev. Biol. 1, 4 (2001).

31. Holling, T. M., Schooten, E. \& van Den Elsen, P. J. Function and regulation of MHC class II molecules in T-lymphocytes: of mice and men. Hum. Immunol. 65, 282-290 (2004).

32. Reizis, B., Bunin, A., Ghosh, H. S., Lewis, K. L. \& Sisirak, V. Plasmacytoid dendritic cells: recent progress and open questions. Annu. Rev. Immunol. 29, 163-183 (2011).

33. Van Kaer, L. NKT cells: T lymphocytes with innate effector functions. Curr. Opin. Immunol. 19, 354-364 (2007).

34. Van Kaer, L., Parekh, V. V. \& Wu, L. Invariant natural killer T cells: bridging innate and adaptive immunity. Cell Tissue Res. 343, 43-55 (2011).

35. Anderson, M. K., Weiss, A. H., Hernandez-Hoyos, G., Dionne, C. J. \& Rothenberg, E. V. Constitutive expression of PU.1 in fetal hematopoietic progenitors blocks $\mathrm{T}$ cell development at the pro-T cell stage. Immunity 16, 285-296 (2002).

36. Ishifune, C. et al. Notch signaling regulates the development of a novel type of Thy1-expressing dendritic cell in the thymus. Eur. J. Immunol. 41, 1309-1320 (2011).

37. Lewis, K. L. et al. Notch2 receptor signaling controls functional differentiation of dendritic cells in the spleen and intestine. Immunity 35, 780-791 (2011).

38. Lieberman, J Granzyme A activates another way to die. Immunol. Rev. 235, 93-104 (2010).

39. Martinvalet, D., Dykxhoorn, D. M., Ferrini, R. \& Lieberman, J. Granzyme A cleaves a mitochondrial complex I protein to initiate caspase-independent cell death. Cell 133, 681-692 (2008).

40. Zangi, L. et al. Deletion of cognate CD8 T-cells by immature dendritic cells: a novel role for perforin, granzyme A, TREM-1 and TLR7. Blood 120, 1647-1657 (2012).
41. Kerkar, S. P. et al. IL-12 triggers a programmatic change in dysfunctional myeloidderived cells within mouse tumors. J. Clin. Invest. 121, 4746-4757 (2011).

42. Zhang, L. et al. Improving adoptive T cell therapy by targeting and controlling IL-12 expression to the tumor environment. Mol. Ther. 19, 751-759 (2011).

43. Kerkar, S. P. et al. Tumor-specific CD8 + T cells expressing interleukin-12 eradicate established cancers in lymphodepleted hosts. Cancer Res. 70, 6725-6734 (2010).

\section{Acknowledgements}

This work was supported by the Intramural Research Program of the Center for Cancer Research, National Cancer Institute, National Institutes of Health. We thank Ulrich H. von Andrian for providing the B16-FLT3L melanoma cell line, Paul R. Mittelstadt for TCR-transgenic and Rémy Bosselut for Thpok-transgenic mice, respectively, Ehydel Castro for assistance with adoptive transfer, Susan H. Garfield for assistance with confocal microscopy, and Xiaolin $\mathrm{Wu}$ and $\mathrm{Li}$ Jia for help with generating and analyzing the microarray data. We also thank Rafi Ahmed for the LCMV Armstrong strain, the NIH Tetramer facility at Emory University for tetramers, and Atef Allam for LCMV preparation.

\section{Author contributions}

M.K. and I.M. performed experiments, M.K., I.M. and J.D.A conceived the research, designed experiments, analyzed results and wrote the paper.

\section{Additional information}

Supplementary Information accompanies this paper at http://www.nature.com/ naturecommunications

Competing financial interests: The authors declare no competing financial interests.

Reprints and permission information is available online at http://npg.nature.com/ reprintsandpermissions/

How to cite this article: Kuka M. et al. Identification and characterization of polyclonal $\alpha \beta-\mathrm{T}$ cells with dendritic cell properties. Nat. Commun. 3:1223 doi: 10.1038/ ncomms2223 (2012). 